\title{
REVISTAMARACANAN
}

Dossiê

\section{Memórias de um pornógrafo: a revista Hustler, a liberdade de expressão e a política nos Estados Unidos (1970-1980)}

\author{
Memoirs of a Pornographer: Hustler magazine, freedom of speech and \\ politics in the United States (1970-1980)
}

\author{
Alexandre Guilherme da Cruz Alves Junior \\ Universidade Federal do Amapá \\ alexandrecruzunifap@gmail.com
}

\begin{abstract}
Resumo: O presente artigo tem por objetivo analisar as memórias de Larry Flynt, fundador e editor-chefe da Hustler magazine, sobre o período de lançamento e consolidação da revista no mercado pornográfico norte-americano nos anos 1970-1980. Além de refletir os grandes debates acerca do comportamento sexual do período, a revista tornou-se um poderoso instrumento de engajamento político utilizado por Flynt para atacar políticos conversadores e importantes figuras religiosas, contribuindo, no final dos anos 1980, para uma ampliação dos limites da liberdade de expressão e imprensa naquele país.
\end{abstract}

Palavras-chave: Estados Unidos; Pornografia; Liberdade de expressão.

\begin{abstract}
This article aims to analyze Larry Flynt's memoirs about the launch of Hustler Magazine and its consolidation in the US pornographic market during the 1970s - 1980s. In addition to reflecting the debates about the sexual behavior of the period, the magazine has become a powerful tool for Flynt's political engagement, attacking conservative politicians and important religious figures, contributing, in the late 1980 s, to an increase of the limits of freedom of speech and press in that country.
\end{abstract}

Keywords: United States; Pornography; Freedom of speech.

Artigo recebido para publicação em: Outubro de 2016

Artigo aprovado para publicação em: Dezembro de 2016 


\section{Introdução}

arry Flynt é considerado atualmente uma importante personalidade pública na defesa dos direitos civis e da liberdade de expressão e imprensa nos Estados Unidos. Figura controversa e polêmica, movimenta em torno de si reações de diferentes sentidos. Grosso modo, pode ser interpretado como herói na defesa dos valores democráticos norte-americanos ou como um misógino que enriqueceu às custas da exploração de corpos femininos vulgarizados nas páginas da revista Hustler.

Este artigo pretende analisar as memórias do editor acerca do nascimento e da consolidação da Hustler magazine, e da utilização da revista, classificada como pornográfica, como instrumento de atuação política e cultural no complexo ambiente social dos anos 1970 e 1980 nos Estados Unidos.

Em 1996, Larry Flynt publicou suas memórias na obra An Unseemly Man: my life as pornographer, Pundit, and social outcast. Ainda naquele ano seria lançado, com grande repercussão e entusiasmo da crítica especializada, o filme "People vs. Larry Flynt", dirigido pelo tcheco radicado nos Estados Unidos, Milos Forman, com produção executiva de Oliver Stone.

De fato, nos anos 1990, Flynt alcançou um importante status como militante pela defesa da liberdade de expressão e imprensa nos Estados Unidos, passando a ser requisitado a dar palestras e conferências em diferentes universidades norte-americanas. Pode-se afirmar que a sua notoriedade ganhou impulso após a vitória na Suprema Corte federal ${ }^{1}$ contra o pastor batista e fundamentalista, Jerry Falwell, em 1988, quando disputaram diferentes visões acerca da Constituição dos Estados Unidos e dos limites da Primeira Emenda. ${ }^{2}$

\section{Larry Flynt e o nascimento da Hustler magazine}

Mesmo com uma análise atenta sobre as duas primeiras décadas da trajetória de vida de Larry Flynt, poucos poderiam imaginar que o menino pobre do Kentucky, nascido nos anos 1940, no seio de uma família despojada de recursos financeiros e com graves problemas de relacionamento, se converteria em um ferrenho defensor do que considera a "verdadeira" interpretação da Constituição dos Estados Unidos. De fato, contraditoriamente, Flynt sempre flertou com a ilegalidade, passando de vendedor de bebidas alcoólicas proibidas, ainda na

\footnotetext{
1 Mais adiante trataremos deste caso específico.

2 A Primeira Emenda (The First Amendment) à Constituição dos Estados Unidos da América é uma parte da Declaração de Direitos (Bill of Rights) dos Estados Unidos da América. Impede, textualmente, o Congresso do país de infringir seis direitos fundamentais: Estabelecer uma religião oficial ou dar preferência a uma dada religião (a "Establishment Clause" que institui a separação entre a Igreja e o Estado); Proibir o livre exercício de qualquer religião; Limitar a liberdade de expressão; Limitar a liberdade de imprensa; Limitar o direito de livre associação pacífica; Limitar o direito de fazer petições ao governo com o intuito de reparar agravos. A Primeira Emenda desautoriza explicitamente apenas o Congresso a interferir nestes pontos. Contudo, ao longo do tempo, os tribunais asseguraram a extensão destas premissas a qualquer ramo do poder judiciário, executivo ou da sociedade civil.
} 
infância, ao ingresso na marinha com apenas 16 anos de idade através de um documento falsificado assinado conscientemente por sua mãe.

Os anos na marinha são recordados como um período de ganho de autoestima, não apenas pelas funções desempenhadas como técnico de radar, mas pelo fato de ter podido viajar por diferentes regiões do planeta e gozar de uma liberdade que até não tinha. Flynt resumiu essa experiência através de três pilares: livros, mulheres e Poker. "Eu já não me sentia como um caipira do Kentucky, mas como um homem do mundo." ${ }^{3}$

Entretanto, após poucos anos, Flynt se apaixonou por uma garota, apelidada Peggy, que viria a ser mais tarde sua esposa por um breve período de tempo, e as longas viagens a serviço tornaram-se desinteressantes e angustiantes: "Eu perdi toda a motivação em ter sucesso na Marinha e me tornei obcecado pelo desejo de sair". ${ }^{4}$

Em 1965, Flynt teve sua primeira filha, Tonya, mas o casamento com Peggy já dava claros sinais de desgaste devido, principalmente, às constantes brigas e confusões entre o casal. ${ }^{5}$ Após o divórcio, Larry Flynt decidiu iniciar seu próprio negócio e comprou o bar Keewee, na cidade de Dayton, Ohio, que pertencia a sua mãe.

\begin{abstract}
Eu tinha curtido em um monte de bares em minha adolescência e achei que tinha um pouco de conhecimento sobre o que fazia alguns terem sucesso e outros fracassarem. Me pareceu que o principal era conhecer seus clientes. [...] Os clientes que eu conhecia melhor, é claro, eram pessoas da classe trabalhadora como eu. [...] Eu nunca me considerei um homem violento, mas meus primeiros meses no bar foram extremamente sangrentos. Mas eu tinha o objetivo de atender a uma clientela de colarinho azul, do tipo que podia beber uma dúzia de cervejas de uma vez. Quando eles se embebedavam, gostavam de brigar. Eram operários, motoristas de caminhão e trabalhadores da construção civil: as pessoas que resolviam suas diferenças no braço. ${ }^{6}$
\end{abstract}

Após três anos de ritmo intenso de trabalho, Flynt começou a sentir o cansaço e a inviabilidade de continuar vivendo daquele modo, muitas vezes passando mais de 24 horas acordado. Decidiu então abrir um bar diferente, que atraísse outros tipos de clientes, com

\footnotetext{
${ }^{3}$ FLYNT, Larry. An Unseemly Man: my life as pornographer, Pundit, and social outcast. Los Angeles: Dove Books, 1996. p. 43. No original: "I no longer felt like a parochial Kentucky hillbilly but a man of the world".

${ }^{4}$ FLYNT, 1966, Op. cit., p. 45. No original: "I lost all motivation to succeed in the navy and became obsessed with the desire to get out".

${ }^{5}$ No final de 1964, Larry Flynt foi preso pela primeira vez após tentar atirar em sua sogra que, segundo ele, manipulava Peggy contra o marido.

${ }^{6}$ FLYNT, 1996, Op. cit., p. 47 - 53. No original: "I had hung out in a lot of bars in my young life and thought I had a little insight into what made some succeed and others fail. It seemed to me that the key was knowing your customers. [...] The customers I knew best, of course, were working-class people like myself. [...] I've never considered myself a violent man, but my first months in the bar bussiness were extraordinarily bloody. But I was aiming to serve a blue-collar clientele, the kind that could drink a dozen beers in one sitting. When they got drunk, they liked to fight. These were factory workers, truck drivers, and construction workers: people who settled differences with theirs fits".
} 
menos violência e confusão: "A violência estava me cansando. Eu estava tendo muitos pedidos para fechar [o bar]". ${ }^{7}$

No final dos anos 1960, bares com dançarinas haviam se tornado um grande fenômeno na Califórnia e, rapidamente, o modelo se espalhou por algumas regiões dos Estados Unidos. Flynt percebeu que não havia nenhum bar desse estilo na costa Leste, e viajou até a Califórnia para conhecer melhor a dinâmica de funcionamento dos Go Go Clubs.

Meus instintos me disseram que o clube deveria ser no centro [da cidade] de Dayton. O entendimento convencional na época considerava o centro da cidade má escolha. Cidades do interior no Leste estavam sendo abandonadas, e suas áreas centrais estavam se desintegrando. No entanto, parecia certo para mim. Fui com a minha intuição. ${ }^{8}$

No final de 1968, Larry Flynt inaugurou a Hustler Club Board of Directors, em Dayton. Cansado das brigas e quebradeiras que ocorriam em seus bares anteriores, Flynt buscou dar um ar mais sofisticado ao novo clube, visando atrair clientes mais "educados". Entretanto, a Hustler Club não significou de fato um afastamento de Larry Flynt de confusões. Se por um lado os clientes mais pobres e violentos ficaram para trás, Flynt, agora, entraria em um patamar diferente de conflitos, possivelmente mais desgastantes que os anteriores. Esses conflitos, entretanto, foram capitalizados por Flynt como propaganda grátis para os seus negócios.

Pouco depois da inauguração da Hustler Club, Flynt passou a receber constantes cobranças do banco no qual havia financiado um empréstimo para a reforma do clube. $\mathrm{Na}$ verdade, Flynt pareceu mais incomodado com as constantes grosserias ao telefone do que com as cobranças.

O cara no telefone me irritou. Eu achei que ele estava sendo arrogante. Mas, mais importante, eu achei que ele estava errado. [...] Eu tinha o dinheiro. Não era que eu não pudesse pagar; era o princípio da coisa. Em um lampejo de inspiração, decidi pagar o banco e ao mesmo tempo conseguir um pouco de publicidade para o clube. ${ }^{9}$

A sacada de Flynt foi, mesmo para os padrões atuais de publicidade, uma grande jogada. Juntou em moedas todo o valor a ser pago ao banco e mandou suas dançarinas, vestidas a caráter, deixar as sacolas de moedas na porta do banco, esparramando-as pela calçada. O fotógrafo do jornal Dayton Daily News publicou o fato, divulgando, assim, de graça,

\footnotetext{
7 FLYNT, 1966, Op. cit., p. 62. No original: "The violence was wearing me down. I'd had too many close calls".

8 FLYNT, 1966, Op. cit., p. 64. No original: "My instincts told me that the club should be located in downtown Dayton. Conventional wisdom at the time considered downtown a bad choice. Inner cities in the East were being deserted, and their central cores were disintegrating. Nevertheless, it seemed right to me. I went with my intuition".

9 FLYNT, 1966, Op. cit., p. 65. No original: "The guy on the phone annoyed me. I thought He was arrogant. But more important, I thought He was wrong. [...] I had the Money. It wasn't that I couldn't pay; it was the principle of the thing. In a flash of inspiration I decided to pay off the bank and get some publicity for the club at the same time".
} 
a Hustler Club. Segundo Flynt, a atitude foi vista com bom humor inclusive pelo gerente do banco.

Em 1973, Flynt já havia aberto oito filiais da Hustler Club em Ohio, com mais de 300 empregados no total. Os clubes passaram a ter um cartão para os membros exclusivos, pois vários clientes viajavam continuamente pelo estado, frequentando diferentes filiais. Assim, para além de descontos em drinks e petiscos, alguns membros ainda ganhavam o serviço de limusine entre o clube e o hotel em que estivessem hospedados.

"Eu comecei a pensar em uma newsletter que apresentaria novas dançarinas e deixaria os membros informados se sua garota favorita tinha se mudado para um clube diferente. ${ }^{10} \mathrm{~A}$ partir dessa ideia relativamente modesta, Flynt plantaria as sementes para o surgimento da revista Hustler.

$\mathrm{Na}$ verdade, Flynt havia observado pouco antes, na entrada da Hi-Liter Club em Phoenix, um folheto informativo, chamado Bachelor's Beat, que circulava entre os clubes noturnos e alguns teatros locais, trazendo matérias sobre saúde, amor, sexo, casamento, etc. O formato, considerado por Flynt despretensioso, chamou atenção do empresário, que vislumbrou o sucesso que a publicação poderia alcançar em Dayton e tornou-se sócio do editor.

De fato, Flynt ficou bastante animado com a produção da publicação, tanto que, após alguns exemplares terem gerado contratos de publicidade, decidiu expandir a circulação para além das casas noturnas de Dayton: "Me pareceu que a melhor maneira de aumentar a circulação era colocar o Beat na rua junto com os jornais de grande circulação". ${ }^{11}$

Entretanto, ao solicitar o registro de permissão para a venda, Flynt viu-se diante de uma surpreendente reação dos setores conversadores de Dayton.

\begin{abstract}
Eles insistiam que a presença da publicação enfraqueceria os princípios morais da comunidade e aumentaria os crimes. Eu não sabia na época que se tratava do mesmo tipo de falso moralismo e babaquice política que eu enfrentaria nos anos seguintes. Eu finalmente consegui a minha licença, mas só depois de muita disputa. Alguém finalmente se lembrou que a Primeira Emenda se aplicava a mim também. Mas a pressão continuou, tanto por parte das autoridades, quanto de vândalos que frequentemente quebravam as prateleiras e, por vezes, as roubavam. ${ }^{12}$
\end{abstract}

O Beat não trouxe grande retorno financeiro, mas serviu como uma espécie de estágio para Larry Flynt, não apenas no que tange às etapas de uma produção editorial, mas também a respeito das forças conservadoras locais que impunham diversas formas de resistência à

\footnotetext{
${ }^{10}$ FLYNT, 1966, Op. cit., p. 72. No original: "I started to think about a newsletter that would introduce new dancers and let members know if their favorite girl had moved to a different club".

${ }^{11}$ Ibid. No original: "It seemed to me that the best way to increase circulation was to put the Beat out on the street along with the mainstream newspapers".

12 FLYNT, 1966, Op. cit., p. 81. No original: "They insisted that the presence of the newpaper would weaken the moral fiber of the community and increase crimes. I didn't know at the time that it was the same kind of false moralism and political bullshit I would face in the years to come. I finally got my permit, but only after much wrangling. Someone finally remembered that the First Amendment appplied to me, too. But the pressure continued, both from the authorities and from vandals who frequently broke the racks and sometimes stole them".
} 
Memórias de um pornógrafo: a revista Hustler, a liberdade de expressão e a política nos Estados Unidos (1970-1980)

circulação de publicações relativas ao sexo. É interessante perceber também como foi nesse momento que a Primeira Emenda norte-americana surgiu como um instrumento para Flynt defender sua perspectiva editorial. Obviamente Flynt não tinha conhecimento das diferentes interpretações e disputas acerca do sentido da Primeira Emenda presentes na história dos Estados Unidos. Provavelmente elas também pouco importariam naquele momento, afinal, Flynt já exercitava a sua própria visão da liberdade de expressão, representativa não só da trajetória individual, mas também dos grupos sociais nos quais circulava.

Com o fim do Beat, Flynt passou a direcionar sua experiência em publicações nos folhetos informativos da Hustler Club. No começo de 1973, a Hustler Newsletter tornou-se uma pequena revista, com aproximadamente 34 páginas.

Segundo Flynt, o embargo do petróleo pelos países árabes em 1973 levou os Estados Unidos a uma recessão repentina, sentida por ele, especificamente, com a queda da presença de clientes em seus clubes noturnos. Foi então que decidiu investir na profissionalização e expansão da revista Hustler.

\begin{abstract}
Eu decidi fazer uma pequena pesquisa. Eu nunca tinha realmente lido uma revista masculina antes. Eu devo ter visto um exemplar da Playboy na minha vida, e eu nunca tinha visto a Penthouse. Eu tinha tanto sexo, onde e sempre que queria, que eu nunca tinha procurado o consolo de revistas masculinas. [...] Então eu fui a uma banca de jornal e comprei cópias de Playboy e Penthouse, levei-as para casa, e as analisei. A primeira coisa que me chamou a atenção foi o conteúdo editorial. Não é muito diferente do que você encontra em revistas tradicionais. Eu entendi rapidamente que o texto não fazia a menor diferença. As imagens eram as responsáveis pelas vendas. Mas, analisando as fotos, me pareceu que algo estava faltando. Ambas as publicações possuíam uma suposição implícita de que os homens gostavam de mulheres com os peitos grandes, bundas grandes, pernas bonitas e rosto perfeito. Até certo ponto, eu pensei, isso é verdade. Mas os homens que eu conhecia, rapazes da classe trabalhadora, se interessavam mais pela genitália feminina. Isto era uma verdade para mim. Senti que se alguém publicasse uma revista mais sintonizada com o que o Joe médio realmente gostava, todo um novo mercado poderia ser criado. [...] Se você tivesse as modelos que abrissem as pernas um pouco mais, você venderia mais revistas. Eu fiz uma nota mental disto. ${ }^{13}$
\end{abstract}

Embora a citação seja relativamente grande, ela torna-se importante, uma vez que Flynt narra sua busca por uma identidade diferenciada da revista Hustler no conjunto de publicações que traziam em suas páginas fotos de mulheres nuas. Flynt imaginou o que

13 FLYNT, 1966, Op. cit., p. 86-87. No original: "I decided to do a little research. I had never really read one men's magazine before. I might have seen one copy of Playboy in my life, and I had never seen Penthouse. I had so much sex, wherever and whenever I wanted it, that I had never sought the solace of men's magazines. [...] So I went to a newsstand and bought copies of Playboy and Penthouse, took them home, and studied them. The first thing that struck me was the editorial contente. It wasn't much different from what you could find in mainstream magazines. I quickly concluded that the text didn't make a damn bit difference. The pictures were responsible for the sales. But in sizing up the fotos, it seemed to me that something was missing. Both publication made the implicit assumption that men are turned on by women with big breasts, great butts, nice legs, and perfect face. As far as it goes, I thought, that's true. But the men I knew, working-class guys, were turned on the most by female genitalia. That was certainly true for me. I felt that if someone published a magazine, more attuned to what the average Joe really liked, a whole new Market could be created. [...] If you got the models to spread their legs a little wider, you'd sell more magazines. I made a mental note of this". 
trabalhadores comuns gostariam de ver, a partir da realidade em que viviam, visto que as modelos que apareciam nas páginas da Playboy e Penthouse eram, de fato, inalcançáveis para a maioria deles.

Como aponta Boulware, a Playboy se caracterizou pela busca constante de sofisticação nas fotos das modelos nuas e nos artigos de variedades que compunham as edições da revista.

Desde o seu lançamento em 1955, até pico de circulação em 1972, com 7 milhões de cópias, a revista manteve-se quase a mesma - jovens mulheres nuas com cinturas finas e seios grandes, conselhos sobre estilo de vida, sobre como ser um cara culto e artigos sobre esportes, religião, nazistas ou a máfia para lembrá-lo que não se tratava apenas de olhar peitinhos. ${ }^{14}$

Segundo Smolla, ${ }^{15}$ tanto a Playboy quanto a Penthouse, as duas principais revistas classificadas como pornográficas pelo mercado editorial norte-americano nos anos 1970, mascaravam, indiretamente, o forte apelo sexual em suas páginas, flertando com a literatura e a arte. Entretanto, a disputa por mercado entre ambas resultou, entre 1970 e o começo de 1972, em uma verdadeira guerra entre Hugh Hefner e Bob Guccione, donos da Playboy e Penthouse respectivamente, consubstanciada em seguidas edições com fotos de capa apresentando o nu frontal feminino, algo bastante ousado para os padrões da época.

Nesse sentido, as disputas entre a Playboy e a Penthouse acerca do nu frontal sinalizavam uma modificação no mercado pornográfico. Não apenas as revistas especializadas passaram a ousar mais em suas fotos, mas percebeu-se um aumento do apelo sexual em outras mídias, como filmes, seriados, músicas, comerciais de TV, peças de teatro, performances artísticas, exposições, etc. Ou seja, embora Flynt valorize em suas memórias a sua capacidade de interpretar os desejos de seu público alvo, é fato que a revista Hustler foi gestada em um ambiente de crescimento do apelo sexual em diversos setores da sociedade norte-americana, o que possibilitou uma linguagem considerada mais agressiva, não apenas pela Hustler, mas em outras revistas, com fotos e histórias mais explícitas.

O diferencial de Flynt, naquele momento, talvez possa ser a sua evidente disposição em avançar continuamente sobre qualquer fronteira moral que se impunha sobre a Hustler, seja advinda de setores conservadores da sociedade norte-americana, como os fundamentalistas cristãos, ou de correntes do feminismo que criticavam o que entendiam como a utilização do corpo feminino como mercadoria.

$\mathrm{Na}$ verdade, Larry Flynt tomou gosto pelo embate com diferentes setores da sociedade norte-americana contrários à sua visão de mundo. Será justamente durante esses conflitos,

${ }^{14}$ BOULWARE, Jack. Sex, American Style: an illustrated romp through the Golden age of heterosexuality. Venice: Feral House, 1997. p. 67. No original: "From its launch in 1955, to a peak of circulation in 1972 of 7 million copies, the magazine remained approximately the same - nude young women with skinny waists and big breasts, lifestyle advice on how to be a cultured guy and articles on sports, religion, Nazis or the mob to remind you it wasn't all just about looking at titties".

${ }^{15}$ SMOLLA, Rodney A. Jerry Falwell v. Larry Flynt: the first amendment on trial. New York: St. Martin Press, 1988. 
alguns apenas retóricos, com xingamentos e ironias, e outros mais sérios e polêmicos, com processos e julgamentos, que o jovem pobre do Kentucky irá sofisticar, ao longo da década, a sua interpretação constitucional e histórica dos Estados Unidos, refletindo-a nas páginas da revista.

\section{A revista Hustler, pornografia, liberdade de expressão e política}

Para Flynt, qualquer um poderia ser um Playboy e ter uma Penthouse. Mas apenas o verdadeiro homem poderia ser um Hustler. ${ }^{16}$

A primeira publicação da Hustler chegou às bancas em julho de 1974. A revista se originou dos informativos Hustler Newsletter e The Hustler for Today's Man, que eram encartes promocionais do clube de strip de Larry Flynt. O então editor executivo Mike Foldes ajudou a conceber a revista e escreveu inúmeros editoriais para Flynt.

O meu princípio norteador foi "dar-lhes o que eles querem". Eu queria
atender às pessoas como elas realmente eram ou deveriam ser. A
pergunta que eu tive que encarar de imediato era se a revista deveria
incluir questões sobre estilo de vida, comentários sobre filmes e
entrevistas com figuras tradicionais, como a Playboy fazia. Meu instinto foi
o de tentar algo diferente. Me pareceu que, se o tema e o foco da revista
é o sexo, então todo o seu conteúdo deveria servir a esse propósito. Se
um cara vai se masturbar olhando para uma página central, ele se
importa sobre que tipo de rádio comprar? Eu queria uma revista sem
pretensões e cheia de fantasia, ficção, sátira e humor mordaz. ${ }^{17}$ (Grifo
nosso)

A revista, inicialmente com poucas vendas e com problemas na distribuição, acabou ultrapassando 1 milhão de vendas em 1975, com a publicação de fotos da ex-primeira dama dos Estados Unidos, Jacqueline Kennedy Onassis, fazendo topless durante uma viagem à Grécia. As fotos foram tiradas por um paparazzo ainda em 1971, e já haviam sido publicadas pela revista italiana Playmen em 1973. Entretanto, nenhuma revista norte-americana tinha aceitado comprá-las, uma vez que desconheciam as reações sociais e políticas que poderiam resultar da publicação de fotos da ex-primeira dama parcialmente nua.

Playboy e Penthouse se negaram a negociar com o paparazzo, que acabou sentando-se à mesa com Larry Flynt. O editor da revista Hustler comprou as fotos por 18 mil dólares e,

\footnotetext{
16 Nos Estados Unidos a palavra hustler pode ser utilizada para adjetivar uma pessoa batalhadora (homem ou mulher), que faz as coisas acontecerem, mas também pode assumir sentido pejorativo, definindo alguém como propenso a negócios ilegais, tráfico de drogas, cafetinagem ou prostituição. Na acepção da revista, hustler significaria um malandro, mas um malandro "espada", sexualmente ativo.

17 FLYNT, 1996, Op. cit., p. 91. No original: "My guiding principles was 'give them what they want'. I wanted to respond to people as they really were or should be. The question I had to face right away was whether the magazine ought to include lifestyle issues, movies reviews, and interviews with mainstream figures, as Playboy did. My instinct was to try something different. It seemed to me that if the theme and focus of a magazine is sex, then its whole content ought to serve that purpose. If a guy is going to jerk off looking at a centerfold, does he care about what kind of stereo to buy? I wanted a sex magazine free of pretense and full of fantasy, fiction, satire, and biting humor".
} 
contrariando as orientações de seus advogados, publicou quatro fotos full-page de Jackie Onassis no interior da revista, preservando a ex-primeira dama apenas de ser capa de uma revista pornográfica.

Aparentemente, Flynt não via nenhum problema em expor, ou até mesmo agredir, celebridades, políticos, denominações religiosas, etc. através da revista Hustler.

\begin{abstract}
Eu queria ofender a todos em condições iguais de oportunidade. Eu decidi fazer charges satirizando negros, brancos, judeus, cristãos, ricos e pobres. Não importava para mim, a quem eu ofendia. Eu queria proporcionar um espaço para o tipo de humor negro que representava os moinhos, fábricas e locais de trabalho das pessoas comuns. Humor sempre foi uma válvula de escape para eles, uma forma de desabafar quando a vida estava difícil. ${ }^{18}$
\end{abstract}

A grande imprensa escrita e televisiva passou a noticiar a vasta busca pela edição da revista que continha as fotos da ex-primeria dama nas bancas. O então governador de Ohio, James Rhodes, foi filmado comprando um exemplar da Hustler. A justificativa dada por Rhodes, na ocasião, foi de que se tratava de uma pesquisa, uma vez que estava escrevendo um livro sobre as primeiras damas dos Estados Unidos. Em 1996, Flynt escreveria: "Eu ainda estou procurando aquele livro". ${ }^{19}$

De algum modo, Flynt percebeu que polêmicas geravam repercussão e mídia, redundando em uma propaganda nacional ${ }^{20}$ da revista sem nenhum custo. Ainda em 1976, na edição de julho, ou seja, durante o mês do bicentenário da independência dos Estados Unidos, a Hustler publicou uma charge de Henry Kissinger, Gerald Ford e Nelson Rockfeller estuprando a Estátua da Liberdade.

Mas o interessante é assinalar que essa percepção das fronteiras no interior da sociedade norte-americana, e o próprio direito à liberdade de expressão, foram adquiridos por Larry Flynt sem nenhuma base teórica, acadêmica ou estudos jurídicos, mas, ao contrário, através das suas experiências individuais e da rede de relações que construiu ao longo da vida.

O enquadramento da sua visão de liberdade de expressão à tradição mais progressista da Primeira Emenda se deu a posteriori, durante as batalhas judiciais nas quais foi envolvido por grupos que compreendiam a liberdade de expressão e as liberdades individuais na sociedade norte-americana de modo mais restrito. "Eu nunca pensei sobre a Primeira Emenda

\footnotetext{
18 FLYNT, 1966, Op. cit., p. 92. No original: "I wanted to offend everyone on na equal-opportunity basis. I decided to run cartoons lampooning blacks, whites, jews, Christians, rich and poor. It didn't matter to me whom I offended. I wanted to provide a forum for the kind of dark humor that characterized the mills, factories, and workplaces of ordinary people. Humor had Always been an escape valve for them, a way to let off steam when life was hard".

19 FLYNT, 1966, Op. cit., p. 100. No original: "I'm still looking for that book".

20 A notícia da publicação das fotos de Jackie Onassis ultrapassou as fronteiras dos Estados Unidos, tornando-se um assunto de repercussão internacional.
} 
e as liberdades civis até que eu estava enfrentando um juiz que poderia me prender por 20 anos." 21

Conforme a revista Hustler ganhava espaço diante do público norte-americano, passou também a chamar a atenção de grupos sociais e políticos conservadores em Ohio e no restante dos Estados Unidos. Para Larry Flynt, a questão central não era necessariamente o conteúdo pornográfico da revista, mas sua posição política: "A Hustler era política e tinha orientação de classe. Por exemplo, eu comecei uma seção chamada 'O Idiota do Mês', em que eu criticava políticos, figuras religiosas - qualquer um na vida pública - que eu achasse que fosse falso ou hipócrita." 22

A charge com importantes figuras públicas estuprando a Estátua da Liberdade, em 1976, causou estupor em autoridades norte-americanas. O então prefeito de Cleveland chegou a marcar uma coletiva de imprensa apenas para condenar a brincadeira considerada de mau gosto.

Entretanto, as reações não parariam por aí.

\begin{abstract}
Eu e Althea [sua segunda esposa] fomos acusados de violações de vários crimes previstos no direito penal de Ohio, junto com o meu gerente de produção, Al Van Schaik, e meu irmão, Jimmy. Em julho de 1976 fomos acusados de cafetinagem, ${ }^{23}$ obscenidade, e crime organizado - tudo por publicar a revista Hustler. Se fossemos condenados, a pena máxima seria de 25 anos de prisão. E a atmosfera em Cincinnatu era hostil - para dizer o mínimo - com relação a Hustler. ${ }^{24}$
\end{abstract}

De fato, a segunda metade dos anos 1970 iria testemunhar o fortalecimento de discursos conservadores, como reação, em parte, às vitórias no âmbito da Suprema Corte de algumas bandeiras dos movimentos pelos direitos civis nos anos anteriores. Em diversas cidades norte-americanas surgiram grupos antipornografia.

Em Cincinnatti, o Citizens for Decency Through Law (CDL), grupo conservador católico liderado por Charles $\mathrm{H}$. Keating, e o promotor Simon Leis Jr, tornaram-se o inimigo número 1 da revista Hustler.

[Charles Keating] empregava seis advogados em tempo integral para ajudar a erradicar o "mal" das bancas de jornal e fornecer apoio jurídico

\footnotetext{
${ }^{21}$ FLYNT, Larry. Sex, Lies \& Politics: The naked truth. New York: Kensington Books, 2004. p. XIII. No original: "I never thought about the First Amendment and civil liberties until I was facing judge who was set on putting me away for twenty years".

22 FLYNT, 1996, Op. cit., p. 121. No original: "Hustler was political and class-oriented. For example, I had started a feature called 'Asshole of the Month', in which I lambasted politicians, religious figures - anyone in the public life - who I thought were phony or hypocritical".

23 Também conhecido como Lenocínio, prática considerada criminosa por explorar, facilitar ou estimular a prostituição.

${ }^{24}$ FLYNT, 1966, Op. cit., p. 122. No original: "Althea and I were charged with several criminal crimes violations of Ohio law there, along with my production manager, Al Van Schaik, and my brother, Jimmy. In July 1976 we were indicted for pandering, obscenity, and organized crime - all for publishing Hustler magazine. We went through a perfunctory ritual in which we turned ourselves in, were arrested and arraigned, posted bond, and were order to appear for trial. [...] If we were convicted, the maximum penalty was twenty-five years in prison. And the atmosphere in Cincinnatu was hostile - to say the least - toward Hustler".
} 
aos procuradores supostamente sobrecarregados. Entre seus serviços estava o de leitura e visualização de revistas pornográficas e filmes que sua organização iria analisar, sintetizar, e colocar à disposição do Ministério Público e legisladores. Assim, a organização fornecia simultaneamente um veículo para seus funcionários perseguirem sua própria obsessão com a obscenidade de uma forma socialmente aceita, e condená-la ao mesmo tempo. Freud teria tido um dia dífícil: vários caras sentados, assistindo filmes pornôs, dizendo: "Deus, isso foi nojento - você rebobinaria o filme e colocaria de novo?"25 (Grifos do autor)

Embora longa, essa passagem é bastante interessante, pois revela a forma irônica com que Flynt caracteriza seus adversários e, ao mesmo tempo, demonstra a sua incapacidade de vê-los atuando a partir de um valor sincero. Para Flynt, seus adversários eram (e possivelmente ainda são) na verdade simplesmente grandes hipócritas. Em última análise, Larry Flynt tornou-se viciado em "desmascarar" a hipocrisia que enxergava nos grupos conservadores dos Estados Unidos, uma vez que para ele, esses grupos atacavam as liberdades fundamentais com as quais a sociedade norte-americana fora constituída.

O grande risco em 1976, para Flynt e para a revista Hustler, era que a Suprema Corte havia abdicado em 1973, durante o julgamento do caso Miller v. California, de definir o que era obsceno, delegando às cortes estaduais a tarefa de fazê-lo, a partir dos valores locais (community standards).

Como aponta Foner, naquele período, de modo geral,

[...] a ênfase conservadora sobre a autonomia governamental das comunidades locais raramente discutia as relações de poder dentro dessas comunidades, e deixava não especificada como os direitos dos dissidentes e das minorias desprezadas seriam protegidos. ${ }^{26}$

A partir de 1976, Larry Flynt percorreu o país para responder a processos estaduais que não se limitavam apenas a processá-lo pela publicação de materiais considerados obscenos, mas também por outras graves acusações, como formação de quadrilha e tráfico de drogas. De fato, como afirmado por Flynt, a experiência de ter que defender sua liberdade de expressão pelos tribunais por todo o país acabou fazendo dele um radical defensor da Primeira Emenda, ou melhor, o defensor de uma interpretação radical da Primeira Emenda.

A notoriedade de Flynt chamou a atenção de Ruth Carter Stapleton, irmã do então presidente Jimmy Carter, que o convidou para um jantar. Ruth pertencia à Congregação Batista do Sul e tornou-se amiga íntima de Larry Flynt. Ainda em 1977, Flynt se converteria ao

\footnotetext{
25 FLYNT, 1966, Op. cit., p. 123. No original: "[Charles Keating] employed six full-time lawyers to help root out the 'evil' from newsstands and provide legal support to supposedly overburdened prosecutors. Among his services was Reading and viewing of pornographic magazines and films that his organization would analyse, summarize, and make available to prosecutors and legislators. Thus the organization simultaneously provided a vehicle for its staff members to pursue their own obsession with smut in a socially sanctioned way and condenm it at the same time. Freud would have had a field day: several guys sitting around watching pornô flicks, saying, 'God, that was disgusting - would you rewind the film and play it again?"'

26 FONER, 1998, Op. cit., p. 314. No original: "The conserative emphasis on self-governing local communities rarely discussed relations of power within such communities, and left unspecified how the rights of dissenters and despised minorities were to be protected".
} 
cristianismo e se tornaria um born again. A conversão de Flynt causou estranheza entre seus pares, principalmente em sua esposa, Althea.

Na prática, Flynt iniciou um processo de alteração completa do perfil de seus negócios. "Minha conversão causou o caos na Hustler". ${ }^{27}$ No curto período em que se tornou evangélico, Flynt comprou jornais de viés tradicional em Los Angeles e na Geórgia, além de impor um regime de comportamento restrito em suas empresas, com uma ferrenha campanha antitabagismo entre seus funcionários e nas páginas da Hustler.

Por outro lado, a revista não abdicou do viés pornográfico, passando a mesclar sexo e religião.

Em todo caso, a justaposição de sexo e salvação não vendeu. Se Flynt estava contando com todos os pastores caídos em luxúria em seus corações, ou todas as prostitutas e cafetões secretamente ansiando pela graça redentora, a combinação de ingredientes simplesmente não funcionou. Os americanos preferem suas obsessões puras. Flynt, finalmente, renunciou à sua conversão. ${ }^{28}$

Os processos contra a revista e contra Flynt continuaram a surgir em diferentes regiões do país. Ainda em 1978, Flynt se preparou para enfrentar um novo processo em Lawrence, Geórgia. "Mesmo tendo nascido de novo [em Cristo], a minha posição sobre a Primeira Emenda não havia mudado. Eu decidi lutar vigorosamente contra o novo indiciamento."29

Diferentemente de outras cidades em que havia estado, não houve grande repercussão sobre a presença de Flynt em Lawrence. A relativa tranquilidade e a falta de protestos contra a pornografia nos arredores do tribunal fizeram com que Flynt se sentisse tranquilo e dispensasse seu guarda-costas. Durante o recesso do julgamento, Flynt e seu advogado, Geene Reeves, saíram do prédio principal e, enquanto caminhavam pela calçada, três tiros foram desferidos contra ambos. Um dos tiros acertou o braço de Reeves, e dois acertaram Flynt.

Como os meus joelhos se dobraram e eu comecei a perder a consciência, o primeiro pensamento que passou pela minha cabeça foi: "Merda! Eu não vou terminar o julgamento hoje!" Era inconcebível para mim que eu pudesse morrer. Então eu desmoronei de cara no chão ao lado Gene e perdi a consciência. ${ }^{30}$ (Grifo do autor)

\footnotetext{
27 FLYNT, 1996, Op. cit., p. 168. No original: "My conversion caused chaos at Hustler".

28 SMOLLA, 1988, Op. cit., p. 39. No original: "In any event, the juxtaposition of sex and salvation did not sell. Whether Flynt was counting on all those fallen ministers with lust in their hearts, or all those prostitutes and pimps secretly, longing for saving grace, the combination of ingredients just didn't make it. American prefers their obsession pure. Flynt eventually renounced his conversion".

${ }^{29}$ FLYNT, 1966, Op. cit., p. 169. No original: "Even though I had been born again, my stance on the First Amendment had not changed. I decided to fight the new indictment vigorously".

${ }^{30}$ FLYNT, 1966, Op. cit., p. 171. No original: "As my knees buckled and I began to lose consciousness, the first thought that went through my mind was, 'Shit! I'm not going to finish the trial today!' It was inconceivable to me that I might die. Then I collapsed face-first on the ground next Gene and lost consciousness".
} 
O atentado contra Larry Flynt gerou uma grande repercussão nacional, principalmente porque a polícia não tinha ideia de quem poderia estar por trás do crime. As dúvidas não eram, obviamente, pela falta de inimigos potenciais de Flynt, mas justamente o contrário. Flynt havia irritado muita gente. Várias foram as especulações na imprensa, passando desde a Ku Klux Klan (KKK), setores da máfia, a até mesmo agentes secretos da CIA, uma vez que Larry Flynt deu inúmeras declarações afirmando levar a cabo uma investigação paralela para revelar o(s) verdadeiro(s) culpado(s) pelo assassinato do então presidente J. F. Kennedy.

Apenas em 1980, quando Joseph Paul Franklin, defensor da supremacia racial branca ligado a KKK, foi preso em Salt Lake City, após atirar e matar dois homens negros de modo aleatório na rua, o atentado contra Flynt foi desvendado. Na verdade, a lista de homicídios confessados por Franklin era assustadora, com 20 assassinatos, incluindo crianças negras e judias, além de outros atentados que não redundaram em morte, como o atentado contra Larry Flynt em 1978. A razão que levou o atirador a tentar matar Flynt havia sido uma publicação na Hustler de fotos de casais inter-raciais simulando sexo.

Em 1997, Joseph Paul Franklin foi condenado à morte no estado do Missouri. Pouco antes de sua execução no dia 20 de novembro de 2013, Larry Flynt veio a público defender o perdão a Franklin. Em carta aberta, publicada no Hollywood Reporter, Flynt afirmou que tinha todas as razões para estar satisfeito com a morte de Franklin, mas que na realidade não estava.

Passei muitos anos numa cadeira de rodas, com tempo para pensar no assunto. Na minha opinião, a única motivação por trás da pena de morte é a vingança, não a justiça, e acredito firmemente que um governo que proíbe homicídios entre seus cidadãos também não se deve dedicar a matar pessoas. ${ }^{31}$

De fato, os tiros causaram danos irreversíveis em sua coluna, colocando-o permanentemente sobre uma cadeira de rodas. No processo de recuperação, Flynt e sua esposa Althea decidiram mudar-se para Los Angeles, onde a Hustler estava terminando de construir um escritório.

Enquanto Flynt se adaptava à nova realidade, Althea ficou à frente dos negócios e abandonou totalmente a abordagem de questões religiosas na revista. Ao mesmo tempo, Althea passou a circular pelas festas da cidade, onde acabou se viciando em heroína. Segundo Flynt, o seu próprio estado de saúde, quase sempre com dores ou sob efeito de sedativos, não permitiu que pudesse interceder pela esposa, que acabou morrendo de overdose no começo da década de 1980 .

31 FLYNT, Larry. Don't execute the man who paralyzed me. In: Hollywood Report. 17/10/2013. No original: "I have had many years in this wheelchair to think about this very topic. As I see it, the sole motivating factor behind the death penalty is vengeance, not justice, and I firmly believe that a government that forbids killing among its citizens should not be in the business of killing people itself". Disponível em: http://www.hollywoodreporter.com/news/larry-flynt-dont-execute-man-649158. Acesso em: 20/12/2013. 
Embora tenha se tornado recluso inicialmente, não tardou para Flynt voltar às batalhas judiciais e aos noticiários. Em 1976, ele fora processado por Bob Guccione, dono da revista Penthouse, e por sua namorada, Keth Keeton, em 39 milhões de dólares por difamação, após publicar uma charge na Hustler, sugerindo que Guccione fosse homossexual, incluindo uma sequência de comentários pejorativos acerca do relacionamento do casal.

Na verdade, Flynt nutria um certo desprezo por Bob Guccione e se utilizava da revista Hustler para atacar o rival.

\begin{abstract}
Uma coisa curiosa sobre meus processos em curso foi o fato de que a Playboy e a Penthouse foram isentas do mesmo tipo de sentimento. Seus respectivos editores, Hugh Hefner e Bob Guccione, sempre tentaram mascarar sua pornografia como arte e justificá-la, incluindo artigos que deveriam ter "relevância social". Eu conheci Hefner e Guccione, e atentei para o fato de que ambos estavam muito desconfortáveis com o que estavam fazendo. Eles queriam ser vistos como respeitáveis, editores importantes [...] "Você pode ser respeitado", eu pensei, "É importante. Mas você ainda pode publicar pornografia". Reconheça isso, tenha orgulho disso, ou saia do negócio. ${ }^{32}$ (Grifos do autor)
\end{abstract}

O processo foi impetrado inicialmente em Ohio e, após apelação de Flynt, o caso acabou prescrito. Keth Keeton e seu advogado, Norman Roy Grutman, que mais tarde iria defender o pastor Jerry Falwell contra Larry Flynt, decidiram então apresentar novo processo em New Hampshire, estado onde o prazo prescricional para crimes de difamação era mais dilatado. A defesa de Flynt recorreu à Suprema Corte, uma vez que nem a Hustler, nem Keth Keeton, que vivia em Nova Iorque, tinham qualquer relação com New Hampshire que justificasse a abertura de processo naquele estado.

O debate sobre competência da Corte de New Hampshire de julgar o caso chegou à Suprema Corte em 1983. Flynt decidiu que não levaria advogados e iria representar a si mesmo. Entretanto, ao chegar a Washington DC, percebeu que a Suprema Corte havia designado um advogado para defendê-lo.

\begin{abstract}
Eu achei que meus direitos estavam sendo pisoteados e fiquei furioso. Conforme os juízes chegaram, parecendo nove sacerdotes solenes em suas vestes judiciais, minha raiva me dominou. Eu gritei da plateia: "vocês não são nada além de oito idiotas e uma boceta!" [Referindo-se à juíza Sandra Day O'Connor]. [O juiz] Burguer virou, apontou para mim e disse: "Prendam esse homem!"33 (Grifos do autor)
\end{abstract}

\footnotetext{
32 FLYNT, 1996, Op. cit., p. 190. No original: "A curious thing about my ongoing prosecutions was the fact that Playboy and Penthouse were exempted from the same kind 0 animus. Their respective publishers, Hugh Hefner and Bob Guccione, always tried to masquerade their pronography as art and justify it by including articles that were supposed to have had so-called 'redeeming social value' [...] I knew Hefner and Guccione and was taken with the fact the both of them were very uncomfortable with what they were doing. They wanted to be looked at as respected, importante publishers. [...] 'You can be respected', I thought, 'and importante. But you still publish pornography. Acknowledge it, be proud of it, or get out of the business'".

33 FLYNT, 1966, Op. cit., p. 192. No original: "I thought my rights had been trampled on and was furious. As the justices rose, looking like nine solemn priests in their judicial vestments, my anger overtook me. I shouted from the audience, 'You're nothing but eight assholes and a token cunt!'. Burguer turned around, pointed at me, and said, 'Arrest that man!'".
} 
De fato, a prisão de Flynt acabou tornando-se um espetáculo. Como não havia transporte adequado para um cadeirante, o editor sugeriu que fosse transportado em sua própria limusine, guiada por um policial. A ideia foi aceita pelos guardas, e formou-se uma caravana de limusines, previamente contratadas por Flynt para transportar seus amigos à Suprema Corte, até a prisão estadual. O juiz Burguer acabou retirando a queixa, e Flynt foi solto.

A posterior decisão da Suprema Corte em permitir que Keth Keeton processasse a revista Hustler em New Hampshire teve grande impacto para toda a imprensa. 0 entendimento da Corte foi que as leis estaduais contra a difamação não tinham apenas a função de proteger indivíduos de ataques da mídia, mas também de proteger seus cidadãos de serem expostos a falsidades e calúnias. Advogados de grupos da imprensa previam que a decisão encorajaria a apresentação de mais processos por difamação e tornaria mais caro e difícil se defender. ${ }^{34}$ Pouco tempo depois, Flynt se envolveria novamente em um embate com o judiciário norte-americano.

No ano de 1982, John Zachary DeLorean, um famoso engenheiro da indústria automobilística, fundador da DeLorean Motor Company Lt, ${ }^{35}$ foi preso pelo FBI sob acusação de importar quase 25 milhões de dólares em cocaína.

Segundo a versão de Larry Flynt,

\begin{abstract}
Um dia, após o noticiário ter transmitido a história, eu recebi um pacote não solicitado de um funcionário anônimo do escritório de advogados de defesa de DeLorean. O pacote continha uma fita de vídeo da detenção e do imediato momento anterior. Foi uma notícia bombástica, mostrando como os agentes do FBI tinham criado uma armadilha para o empresário desesperado. Depois de ver a fita, eu decidi que ela deveria ser vista por uma audiência nacional. A ideia do nosso governo criar armadilhas para pessoas - atraindo-as para o crime para depois prendê-las - realmente me irritou. Sem o envolvimento do FBI não teria havido nenhum crime. Seu agente ao mesmo tempo forneceu a cocaína e sugeriu que sua venda seria a resposta para os problemas [financeiros] de DeLorean. ${ }^{36}$ (Grifo do autor)
\end{abstract}

Larry Flynt entrou em contato com Don Hewitt, produtor do programa "60 Minutes", e mostrou-Ihe cópias do vídeo. Hewitt quis saber a origem das provas, mas Flynt, embora

\footnotetext{
${ }^{34}$ Cf. GREENHOUSE, Linda. High Court rules libel suits may be filed in distant jurisdictions. In: New York Times. 21/3/1984. Disponível em: http://www.nytimes.com/1984/03/21/us/high-court-rules-libel-suitsmay-be-filed-in-distant-

jurisdictions.html?module =Search\&mabReward =relbias\%3Ar\%2C\%7B\%222\%22\%3A\%22RI\%3A18\%22 \%7D. Acesso em: 20/10/2014.

35 O modelo DeLorean DMC12 foi adaptado para a trilogia de filmes "De Volta para o Futuro" (Back to the Future) nos anos 1980, ganhando fama mundial e adoradores até os dias atuais.

36 FLYNT, 1996, Op. cit., p. 196-7. No original: "One day, after the newscast had broadcast the story, I received an unsolicited package from an anonymous clerk in the offices of Delorean's defense attorneys. The package contained a videotape of the arrest and the event immediately preceding it. It was a bombshell, showing how the FBI agents had entrapped the desperate entrepreneur. After viewing the tape, I decided that it should be seen by a national audience. The idea of our government entrapping people - luring them into crime and then arresting them - really upset me. Without the FBI's involvement there would have been no crime. Its agent both supplied the cocaine and suggested that its sale was the answer to DeLorean's problems".
} 
aparentemente não soubesse, passou a utilizar o discurso corrente na imprensa de não revelar suas fontes.

O juiz federal, Robert Takasugi, solicitou a presença de Flynt ao tribunal para esclarecer a origem das fitas. Flynt não tinha intenção alguma de revelar sua fonte. Para ele, o interrogatório parecia "insolente".

\begin{abstract}
Ninguém tinha o direito de perguntar a um editor ou jornalista sobre suas fontes confidenciais. Eu comecei a divagar, falando sobre outras fitas que tinham chegado ao meu poder. "O que isso tem a ver com a fita de DeLorean?", Takasugi interrompeu, sua paciência tinha acabado. "Oh nada, sua excelência", eu respondi. ${ }^{37}$ (Grifos do autor)
\end{abstract}

O juiz Robert Takasugi então multou Flynt em 10 mil dólares por dia até revelar sua fonte. $\mathrm{O}$ que, de fato, pode ser interpretado como um grave ataque à liberdade de imprensa. $\mathrm{Na}$ tarde seguinte, enquanto Flynt dava uma entrevista para a Vanity Fair, seus advogados avisaram que ele deveria estar, em menos de uma hora, diante de Takasugi.

Flynt apresentou-se diante do juiz usando uma bandeira dos Estados Unidos como fralda. Embora Takasugi não tenha dado nenhuma opinião sobre a vestimenta no dia, posteriormente Flynt foi processado por profanação da bandeira, sendo condenado a 15 meses de prisão, dos quais cumpriu apenas seis, na prisão psiquiátrica de Springfield, Missouri.

O caso DeLorean, que mais tarde teve as acusações retiradas, demonstra a importância pública que a figura de Larry Flynt ganhara ao longo de seis anos de embates judiciais em diferentes partes dos Estados Unidos. Embora atualmente Flynt diga que não sabia exatamente a origem das fitas, o que pode ser verdade ou não, o fato é que as fitas chegaram às suas mãos, indicando que, de alguma forma, ele era alguém considerado capaz de levá-las a público.

Outro fato relevante, nesse período, foi a capacidade que Flynt teve de aproveitar-se dos momentos diante do judiciário norte-americano, com a mídia em geral observando sua atuação, não apenas para defender sua interpretação da Primeira Emenda, mas também para divulgar a marca da revista Hustler, combinando, com interessante maestria, a luta pelo que considerava seus direitos individuais e business.

O ano de 1983, na verdade, assistiu a um Larry Flynt cada vez mais atuante. Uma nova cirurgia reduziu drasticamente suas constantes dores, dando-Ihe energia para envolver-se cada vez mais em assuntos públicos. No final daquele ano, Flynt lançaria seu próprio nome para as primárias presidenciais pelo Partido Republicano, criticando ferozmente o então presidente Ronald Reagan, a quem chamava de nuclear-mad cowboy. Na verdade, a candidatura não prosperou, mas representou um momento importante nas atuações públicas de Larry Flynt.

37 FLYNT, 1966, Op. cit., p. 199. No original: "It seemed insolent to me. No one had the right to ask a publisher or journalist about his confidential sources. I began to ramble, talking about other tapes that had come into my possession. 'What does this have to do with the DeLorean tape?', Takasugi boomed, his patience having run out. 'Oh nothing, Your honor', I replied". 
Podemos destacar que, no final dos anos 1970 e início dos anos 1980, embora Flynt fosse bastante irônico e agressivo nas páginas da Hustler, atacando políticos e personalidades da mídia, predominou uma posição pública que podemos classificar como "defensiva". Ou seja, Flynt era comumente processado em diferentes estados e, durante os julgamentos, defendia sua interpretação acerca da liberdade de expressão e de imprensa: para ele, em suma, estas só fariam sentido se fossem ofensivas. Porém, em 1983, Larry Flynt voltou sua atenção ao influente pastor batista e fundamentalista Jerry Falwell.

Falwell era conhecido nacionalmente através de seus programas de rádio e televisão. Ainda em 1979, passou a liderar o grupo político conservador, Moral Majority, base eleitoral do então candidato republicano à presidência dos Estados Unidos, Ronald Reagan. O pastor atacava constantemente na mídia o que considerava as principais causas para a decadência moral dos Estados Unidos: feministas, homossexuais e pornografia. ${ }^{38}$

$\mathrm{Na}$ verdade, esse período marcou a ascensão da pornografia como um dos principais inimigos do conservadorismo religioso. Grupos localizados passaram a lutar em âmbito local contra obras que consideraram pornográficas e obscenas.

\begin{abstract}
A década de 1970 serviu de terreno fértil para o cultivo da nascente plataforma dos "valores familiares". A ideologia da Guerra Fria tinha posto as saudáveis famílias americanas como um baluarte crítico contra o comunismo, e com o declínio da posição global dos Estados Unidos em face do fracasso no Vietnã, o embargo do petróleo da OPEP, e outras debacles, apoiar a família americana, uma instituição outrora venerável, mas abalada pela revolução sexual, assumiu uma importância social e política recém-descoberta pelos conservadores religiosos. ${ }^{39}$ (Grifo do autor)
\end{abstract}

Na percepção de Flynt, Falwell representava "o maior hipócrita dos Estados Unidos" e alguém deveria pará-lo. Jerry Falwell não tolerou uma sátira publicada na última página da revista Hustler, na edição de novembro de 1983. A sátira, intitulada "Jerry Falwell fala sobre sua primeira vez", continha uma entrevista fictícia na qual o pastor afirmava que perdera a virgindade após ter se embriagado, numa relação incestuosa com sua mãe. Tal sátira fazia parte de uma série de propagandas do licor Campari veiculadas na revista Hustler, publicando entrevistas fictícias com diferentes personalidades da música, da televisão e da política, onde estas associavam o prazer de suas primeiras experiências sexuais ao prazer de provar uma dose do licor.

\footnotetext{
38 Para uma análise mais apurada das ideias de Falwell. Cf. FALWELL, Jerry. Listen, America: a conservative blueprint for America's moral rebith. New York: Doubleday, 1980.

39 STRUB, Whitney. Pervesion for Profit: The politics of pornography and the rise of the New Right. NY: Columbia University Press, 2010. p. 181. No original: "The 1970s provided fertile ground for the cultivation of the nascent 'family values' platform. Cold war ideology had posited healthy American families as a critical bulwark against communism, and with America's global position declining in the face of failure in Vietnam, the OPEC oil embargo, and other debacles, shoring up American Family, a oncevenerable institution left shaken by the sexual revolution, took on newfound social and political importance for religious conservatives".
} 
Em entrevista para a produção de material para esse trabalho, Larry Flynt revelou que o motivo para atacar a mãe de Jerry Falwell na paródia foi o fato de que a mãe de um de seus advogados, no início dos anos 1980, enviava todo o dinheiro recebido da seguridade social para a Thomas Road Baptist Church, igreja fundada por Falwell nos anos 1950, e quando seus familiares tentaram reaver os valores, não conseguiram.

\begin{abstract}
Por dez anos ele me culpou por todo o mal encarnado na sociedade. E o tempo todo ele estava tomando o dinheiro dessas pobres senhoras e voando em seu avião, entendeu? Vivendo a alta sociedade, entendeu? E não se importando em nada com elas. Eu pensei: "Esse cara é tão falso, alguém precisa derrubá-lo do seu pedestal". E foi isso que eu tentei fazer. $^{40}$ (Grifo do autor)
\end{abstract}

Embora houvesse um asterisco ao lado do título da paródia, afirmando tratar-se de uma brincadeira, o pastor Jerry Falwell processou Larry Flynt por uso de sua imagem sem consentimento, danos à sua imagem pública e graves danos psicológicos, pedindo 45 milhões de dólares de indenização.

O processo iniciado por Jerry Falwell tornou-se uma das mais importantes querelas judiciais contemporâneas dos Estados Unidos, extrapolando o terreno jurídico e tornando-se uma interessante disputa entre diferentes correntes interpretativas da Constituição e da identidade norte-americana, gerando um importante debate naquela sociedade acerca dos limites da Primeira Emenda e também da delimitação de fronteiras entre religião e Estado, direito individual e direito coletivo.

Segundo Smolla, ${ }^{41}$ parte da sociedade norte-americana não considerava que a liberdade de expressão pudesse ser aplicada à revista Hustler, com uma pornografia classificada como agressiva e abusiva. Por outro lado, para os defensores da revista, a Hustler levava os norteamericanos ao limite da sua tolerância, o que seria benéfico para a democracia.

O caso chegou à Suprema Corte federal e gerou grande interesse da imprensa. Embora os principais jornais não pretendessem associar suas imagens à Hustler, uma vitória do pastor Jerry Falwell poderia gerar uma explosão de processos pelo país por qualquer figura pública citada pelos jornais.

O chefe da Suprema Corte, William Rehnquist, iniciou a leitura da decisão, em 24 de fevereiro de 1988, fazendo uma revisão cronológica do caso. Segundo o juiz, o caso envolvia os limites do Estado, através da Primeira Emenda, de proteger os seus cidadãos de estresses emocionais provenientes de discursos públicos e, ao mesmo tempo, proteger a livre circulação de ideias.

\footnotetext{
40 Entrevista concedida para esta pesquisa em 29 de janeiro de 2013. No original: "For ten years he preached about me blaming me for every evil society embodied. And all the time he was taking these poor old ladies money and flying around his jet airplane, you know?? Living the high life, you know? And not caring anything about them. I just thought this guy is so phony somebody needs to bring him down from his pedestal. And that's what I tried to do".

${ }^{41}$ SMOLLA, 1988, Op. cit.
} 
No coração da Primeira Emenda está o reconhecimento da importância fundamental da livre circulação de ideias e opiniões sobre assuntos de interesse público. A liberdade de alguém falar o que tem em mente não é apenas um aspecto da liberdade individual - e, portanto, um bem em si mesmo -, mas também é essencial para a busca comum da verdade e da vitalidade da sociedade como um todo. ${ }^{42}$

Podemos perceber, logo no argumento inicial, que a Corte entendeu o caso como uma tensão entre direito individual e direito coletivo. A grande questão era justamente encontrar um equilíbrio entre ambos, algo que, de certo modo, as decisões anteriores da Suprema Corte não haviam estabelecido.

A Corte chegou a comparar as sátiras da revista Hustler à longa tradição de chargistas norte-americanos com discursos sociais e políticos ácidos. Entretanto, na continuação da leitura da decisão, Rehnquist buscou construir uma diferenciação que, em contrapartida, não seria suficiente para condenar a sátira contra Falwell.

O requerente alega, no entanto, que a caricatura aqui em questão foi tão "ultrajante" que a distingue das charges políticas mais tradicionais. Não há dúvida de que a caricatura do entrevistado e sua mãe publicada na Hustler é, na melhor das hipóteses, um primo distante das charges políticas descritas acima. [...] Se fosse possível mediante 0 estabelecimento de um padrão de princípios separar um do outro, o discurso público sofreria provavelmente pouco ou nenhum dano. Mas duvidamos que exista tal padrão, e estamos certos de que a descrição pejorativa "ultrajante" não fornecer um [...] O fato de que a sociedade possa considerar ofensivo um discurso não é razão suficiente para suprimi-lo. [...] Para isso, é um princípio central da Primeira Emenda que o governo deva manter-se neutro no mercado de ideias. ${ }^{43}$ (Grifos do autor)

Outro ponto importante dessa decisão, com reflexos em diversas áreas da imprensa, da televisão e do cinema, foi a não proteção de figuras públicas aos discursos "ultrajantes".

Conclui-se que as figuras públicas e os funcionários públicos não podem recorrer ao delito de imposição intencional de sofrimento emocional em razão de publicações como o que aqui está em causa, sem demonstrar,

\footnotetext{
42 Hustler Magazine $v$ Jerry Falwell 485 US 64 (1988). Disponível em: http://www.law.cornell.edu/supremecourt/text/485/46. Acesso em: 13/5/2012. No original: "At the heart of the First Amendment is the recognition of the fundamental importance of the free flow of ideas and opinions on matters of public. The freedom to speak one's mind is not only an aspect of individual liberty - and thus a good unto itself -- but also is essential to the common quest for truth and the vitality of society as a whole".

43 Id. No original: "Respondent contends, however, that the caricature in question here was so "outrageous" as to distinguish it from more traditional political cartoons. There is no doubt that the caricature of respondent and his mother published in Hustler is at best a distant cousin of the political cartoons described above. [...] If it were possible by laying down a principled standard to separate the one from the other, public discourse would probably suffer little or no harm. But we doubt that there is any such standard, and we are quite sure that the pejorative description "outrageous" does not supply one. [...] The fact that society may find speech offensive is not a sufficient reason for suppressing it. [...] For it is a central tenet of the First Amendment that the government must remain neutral in the marketplace of ideas".
} 
além disso, que a publicação contém uma falsa declaração de fato feita com malícia real. ${ }^{44}$

Dessa forma, a Suprema Corte, por 8 votos a 0,45 inocentou de todas as acusações a revista Hustler e seu editor Larry Flynt. A imprensa de modo geral aplaudiu a decisão. Paul McMasters, falando pela Sociedade de Jornalistas Profissionais, afirmou: "É fácil defender a boa conversa de pessoas agradáveis, mas a Primeira Emenda protege todo o discurso, até mesmo os ultrajantes". ${ }^{46}$

Segundo Flynt, a decisão foi surpreendente, uma vez que ele havia, anos antes, xingado praticamente todos os juízes que participaram da decisão. Entretanto, sua tese havia vencido: a Primeira Emenda serve para proteger os discursos ofensivos. Uma interpretação bem diferente da que originou a Primeira Emenda.

O interesse pelo caso, presente em cursos de Direito nos Estados Unidos até os dias atuais, antes de representar uma vitória da tese de Flynt, demonstra que o debate está em aberto, e que a Primeira Emenda será, durante ainda muito tempo, objeto de disputa entre diferentes culturas políticas norte-americanas.

\section{Conclusão}

O presente artigo buscou compreender, através das memórias de Larry Flynt, como o editor inseriu a revista pornográfica Hustler no mercado norte-americano e passou a utilizá-la como instrumento para debates culturais e políticos. De certo modo, Flynt contribuiu também para recuperar uma histórica relação entre pornografia, cultura e política. ${ }^{47}$

A trajetória de Larry Flynt nos revela como a tradição popular de uma liberdade individual e de expressão irrestritas permeia setores da sociedade norte-americana. Flynt elaborou sua ideia de liberdade sem qualquer estudo formal, mas, ao contrário, forjou-a na convivência com os setores mais populares da sociedade norte-americana.

A irritação de Larry Flynt na obra de 1996, ao afirmar que Falwell ainda buscava reverter a decisão de 1988, é sintomática. Os avanços sociais e o atual entendimento constitucional da Primeira Emenda não estão cristalizados. A história da Primeira Emenda não é uma história evolucionista, indo do entendimento mais restrito para o entendimento mais

\footnotetext{
${ }^{44}$ Id. No original: "We conclude that public figures and public officials may not recover for the tort of intentional infliction of emotional distress by reason of publications such as the one here at issue without showing, in addition, that the publication contains a false statement of fact which was made with actual malice".

$45 \mathrm{O}$ juiz Anthony Kennedy não tomou parte no julgamento.

46 TAYLOR, Stuart. Court, 8 - 0, extends right to criticize those in public eye. In: New York Times. 24/2/1988. Disponível em: http://www.nytimes.com/1988/02/25/us/court-8-0-extends-right-to-criticizethose-in-public-eye.html?pagewanted=1. Acesso em: 20/9/2012. No original: "It's easy to stand up for nice talk from nice people, but the First Amendment protects all speech, even the outrageous".

47 Cf. HUNT, Lynn. Obscenidades e as Origens da Modernidade, 1500-1800. In: HUNT, Lynn. A Invenção da Pornografia. São Paulo: Hedra, 1999.
} 
amplo; é justamente a história de disputas entre essas diferentes interpretações constitucionais e, no sentido lato, da própria história e identidade dos Estados Unidos.

Alexandre Guilherme da Cruz Alves Junior: Doutor e mestre em História pelo Programa de Pós-graduação em História da Universidade Federal Fluminense (UFF) e bacharel e licenciado em História pela Universidade Federal Fluminense (UFF). Atua na área de História das Américas, com ênfase em História dos Estados Unidos. Atualmente é professor de História da América da Universidade Federal do Amapá, campus Binacional do Oiapoque, onde desenvolve pesquisas sobre conflitos judiciais entre diferentes culturas políticas nos Estados Unidos e integra o corpo docente do mestrado profissional em História (PROFHISTÓRIA) da mesma universidade. 